\title{
Luminescence and Crystal-Field Analysis of Europium and Terbium Complexes with Oxydiacetate and 1,10-Phenanthroline
}

\author{
Jun-Gill Kang ${ }^{*}$ and Tack-Jin Kim \\ Department of Chemistry, Chungnam National University, Daejeon 305-764, Korea. *E-mail: jgkang@cnu.ac.kr \\ Received February 4, 2005
}

\begin{abstract}
Photoluminescence (PL) spectra of Eu(III) and $\mathrm{Tb}$ (III) complexes with mixed oxydiacetate (ODA) and 1,10phenanthroline (phen) ligands and with homoleptic ODA reveal characteristic line-splitting at $10 \mathrm{~K}$, depending on the site-symmetry of the lanthanide ion in the complex. The energy-level schemes of the ${ }^{7} \mathrm{~F}_{\mathrm{J}}$ states and the emitting levels for $\mathrm{Eu}(\mathrm{III})$ and $\mathrm{Tb}(\mathrm{III})$ ions have been proposed by simulating the line splitting in the framework of crystal-field Hamiltonian. The sets of refined crystal-field parameters for the experimentally determined sitesymmetry satisfactorily reproduce the experimental energy-level schemes. In addition, the PL quantum yield and the decay time were determined at room temperature. The PL quantum yields of $\left[\mathrm{Eu}(\mathrm{ODA}) \cdot(\mathrm{phen}) \cdot 4 \mathrm{H}_{2} \mathrm{O}\right]^{+}$ and [ $\mathrm{Tb}(\mathrm{ODA}) \cdot($ phen $\left.) \cdot 4 \mathrm{H}_{2} \mathrm{O}\right]^{+}$in the crystalline state $(Q=17.7$ and $Q=56.6 \%$, respectively) are much greater than those of $\left[\mathrm{Eu}(\mathrm{ODA})_{3}\right]^{3-}$ and $\left[\mathrm{Tb}(\mathrm{ODA})_{3}\right]^{3-}(Q=1.1$ and $Q=1.3$, respectively), due to the energy transfer from phen to the lanthanide ion. In the aqueous state, the relaxation of the phen moiety due to the solvent results in the reduction of the quantum yield and the shortening of the lifetime.
\end{abstract}

Key Words : Europium, Terbium, Oxydiacetate, 1,10-Phenanthroline, Crystal-field parameters

\section{Introduction}

Europium and terbium complexes emitting red and green luminescence, respectively, have attracted great interest, due to their unique luminescence properties such as hypersensitivity to the coordination environment, narrow bandwidth and long lifetime of millisecond range. ${ }^{1,2}$ The absorption coefficients of these ions, however, are very small. In an effort to obtain high-efficient luminescence, an organic ligand has been introduced as a sensitizer to complexes of these metals. Typical ligands used by several researchers are the combination of $\beta$-diketons and phen. ${ }^{3}$ ODA has the simplest polycarboxylate structure, but is a versatile complexing agent with five potential oxygen-donor atoms. Accordingly, structural and optical properties of the lanthanide complexes with ODA have been extensively studied. ${ }^{4}$ Until now, however, those of rare earth complexes with mixed ODA and phen ligands have not been reported. ${ }^{5}$

Especially in the solid state, the excitation and the luminescence spectra of trivalent lanthanide complexes, responsible for the $\mathrm{f} \rightarrow \mathrm{f}$ transitions, consists of groups of sharp lines. The crystal-field potential plays a key role in the optical processes of the lanthanide ions, since the extent to which the $(2 J+1)$ degeneracy is removed depends upon the site symmetry. Among the lanthanide ions, the $\mathrm{Eu}(\mathrm{III})$ ion offers a convenient facility in the interpretation of the luminescence property in conjunction with the structural configuration, since it has a non-degenerate emitting ${ }^{5} \mathrm{D}_{0}$ state. The electronic terms of $\mathrm{Tb}(\mathrm{III})$ are reversed to those of $\mathrm{Eu}(\mathrm{III})$, with ${ }^{7} \mathrm{~F}_{6}$ as the ground state and ${ }^{5} \mathrm{D}_{4}$ as the emitting level. Although the luminescence spectrum of $\mathrm{Tb}(\mathrm{III})$ is very complicated, the crystal-field analysis for $\mathrm{Tb}$ (III) complex is very challengeable. In this study, we prepare Eu(III) and $\mathrm{Tb}$ (III) complexes using ODA as a bridging chelate and phen as a sensitizer, and characterize their luminescence properties, such as the line splitting, the photoluminescence (PL) quantum yield and the decay time. The energy-level structures of the ${ }^{7} \mathrm{~F}_{\mathrm{J}}$ states of $\mathrm{Eu}(\mathrm{III})$ and $\mathrm{Tb}(\mathrm{III})$ in the complexes are derived by simulating the phenomenological crystal-field splitting with the determined site-symmetry. Luminescence properties of $\mathrm{Eu}(\mathrm{III})$ and $\mathrm{Tb}(\mathrm{III})$ complexes with homoleptic ODA ligands are also investigated in order to characterize the sensitized luminescence of the Eu(III) and $\mathrm{Tb}(\mathrm{III})$ complexes with mixed ODA and phen.

\section{Experimental Section}

$\mathrm{ODAH}_{2}(2 \mathrm{mmol})$ was added to a solution of $1 \mathrm{mmol}$ of $\mathrm{LnCl}_{3} \cdot 6 \mathrm{H}_{2} \mathrm{O}(\mathrm{Ln}=\mathrm{Eu}$ or $\mathrm{Tb})$ and and $1 \mathrm{mmol}$ of 1.10 phenanthroline (phen) in water $(10 \mathrm{~mL})$. The $\mathrm{pH}$ of the solution was adjusted to between 5 and 6 with dilute $\mathrm{NaOH}$. Colorless prismatic crystals of the complex were grown from the resultant solution by the slow evaporation method. The quantitative analysis and the TGA and X-ray crystallographic data showed that the formula of the $\mathrm{Ln} / \mathrm{ODA} / \mathrm{phen}$ crystals was $\left[\mathrm{Ln}(\mathrm{ODA})(\right.$ phen $\left.) \cdot 4 \mathrm{H}_{2} \mathrm{O}\right] \mathrm{Cl} \cdot 5 \mathrm{H}_{2} \mathrm{O}$. Colorless prismatic crystals of $\mathrm{Ln} / \mathrm{ODA}(\mathrm{Ln}=\mathrm{Eu}$ and $\mathrm{Tb})$ were also grown from the mother solution of a $1: 3$ molar ratio of $\mathrm{LnCl}_{3} \cdot 6 \mathrm{H}_{2} \mathrm{O}$ to $\mathrm{ODAH}_{2}$ by the slow evaporation method. The $\mathrm{pH}$ of the mother solution was adjusted at 5-6 with a mild $\mathrm{NaOH}$ solution. The quantitative analysis and the TGA and X-ray crystallographic data showed that the formula of the $\mathrm{Ln} /$ ODA crystals was $\mathrm{Na}_{3}\left[\mathrm{Ln}(\mathrm{ODA})_{3}\right] \cdot 8 \mathrm{H}_{2} \mathrm{O}$.

The PL and excitation spectra were measured at $90^{\circ}$ angle with an ARC $0.5 \mathrm{~m}$ Czerny-Turner monochromator equipped with a cooled Hamamatsu R-933-14 PM tube. The sample was irradiated with an $\mathrm{He}-\mathrm{Cd}$ 325-nm laser line or the light from an Oriel $1000 \mathrm{~W}$ Xe lamp (working power, $400 \mathrm{~W}$ ) 


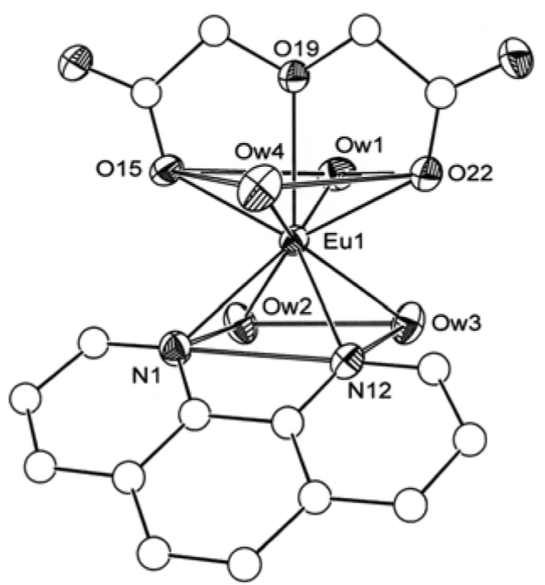

(a)

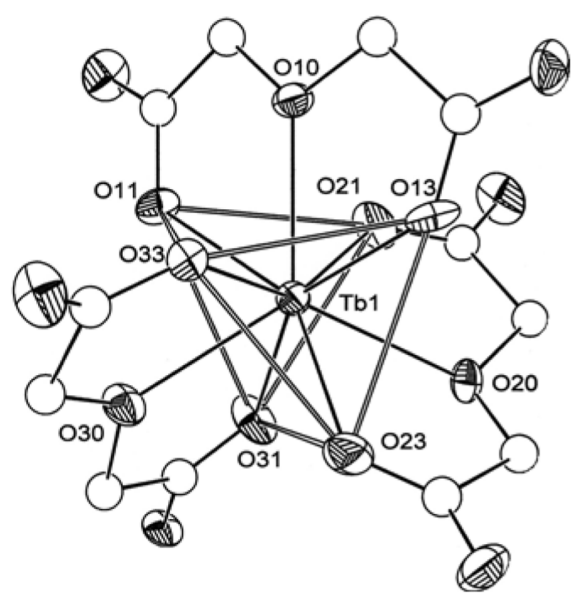

(b)

Figure 1. View of the polyhedra of $\left[\mathrm{Eu}(\mathrm{ODA})(\mathrm{Phen}) \cdot 4 \mathrm{H}_{2} \mathrm{O}\right]^{+}(\mathrm{a})$ and $\left[\mathrm{Tb}(\mathrm{ODA})_{3}\right]^{3-}$ ions showing atom labeling and ellipsoids at $50 \%$.

passing through an Oriel MS257 monochromator. To measure low-temperature luminescence and excitation spectra, the samples were placed on the cold finger of a closed-cycle helium refrigerator (CTI-cryogenics). To determine the decay time, we used a time-correlated single photon counting system with an Edinburg FL 900 spectrophotometer.

The quantum yield, defined by

$$
Q=\frac{\text { number of photons emitted }}{\text { number of photons absorbed }}
$$

was determined based on the method described previously. ${ }^{6,7}$ The recorded spectra for the quantum yield were corrected for the spectral response of the system using an Oriel 45-W quartz tungsten halogen lamp standard. All measurements were repeated 3 times. No significant experimental error was found.

\section{Results and Discussion}

Site Symmetry and Luminescence Property. As shown in Figure 1(a), the [Eu(ODA)(Phen) $\left.4 \mathrm{H}_{2} \mathrm{O}\right]^{+}$complex forms a nine-coordinated polyhedron. The details of the crystallographic data for the complexes will be published elsewhere. ${ }^{8}$ As the case of Er(III) complex with ODA and phen, the polyhedron of the titled complexes adapts the capped square antiprism (CSAP) geometry instead of the tricapped trigonal prism (TCTP) one, frequently observed in the 9 coordinate complexes. ${ }^{9}$ The CSAP geometry can be accessed by the two rectangular faces and the oxygen atom of ether occupying the capping position. For the $\mathrm{Eu}(\mathrm{III})$ complex, the composing atoms in the upper and the lower faces are displaced from their mean planes by $0.064-0.070 \AA$. The displacement of each atom from the mean plane indicates that the Eu(III) complex forms a slightly distorted capped square polyhedron with the $\mathrm{C}_{2 \mathrm{v}}$ symmetry. The polyhedron of the $\mathrm{Tb}$ (III) complex is very similar to that of the Eu(III) complex. For $\left[\operatorname{Ln}(\mathrm{ODA})_{3}\right]^{3-}$, the complex crystallizes in the monoclinic space group $C c$. As shown in Fig. 1(b), the $\left[\mathrm{Tb}(\mathrm{ODA})_{3}\right]^{3-}$ complex forms the
TCTP geometry via the three rectangular and the two triangular faces of the trigonal prism and the three central oxygen atoms occupying the capping positions. The dislocation of the composing atoms from their mean planes ranges from $0.017 \AA$ to $0.021 \AA$. This implies that the $\left[\mathrm{Tb}(\mathrm{ODA})_{3}\right]^{3-}$ polyhedron is slightly distorted from the ideal TCTP with
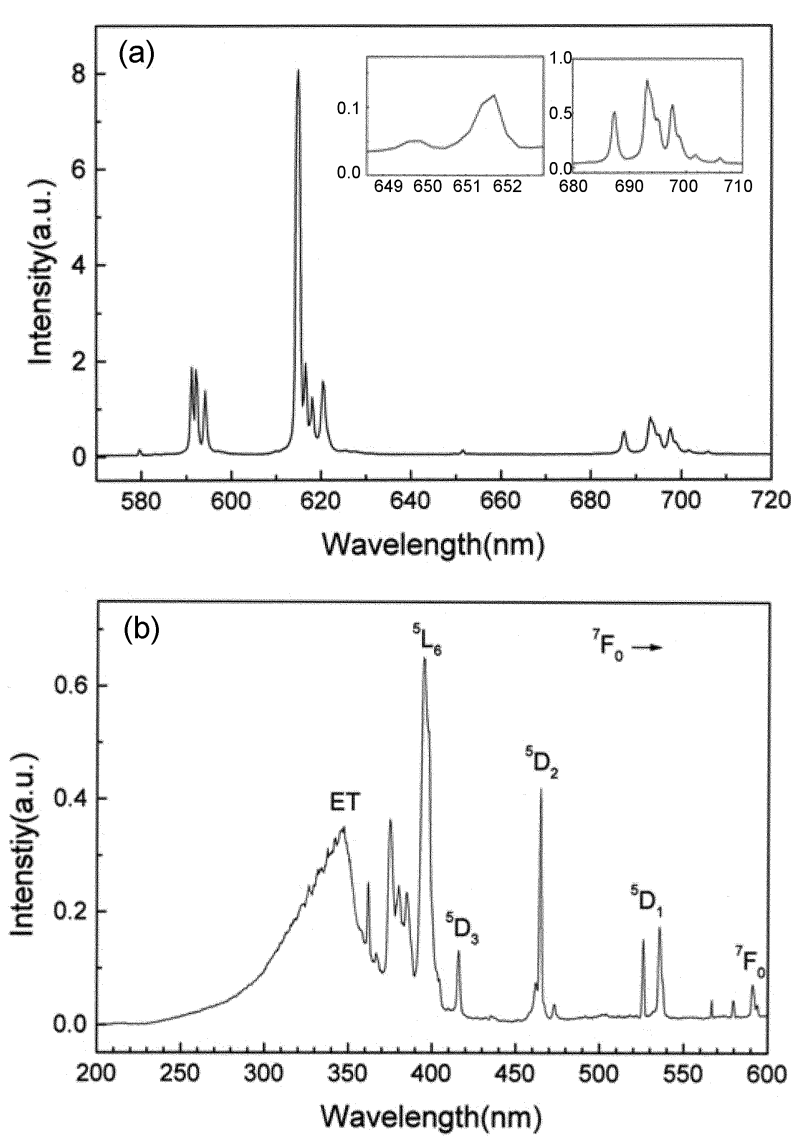

Figure 2. PL (a) and excitation (b) spectra of [Eu(ODA)(Phen). $\left.4 \mathrm{H}_{2} \mathrm{O}\right]^{+}$crystals at $10 \mathrm{~K}$ : (a) $\lambda_{\text {exc }}=325 \mathrm{~nm}$ laser and (b) $\lambda_{\text {ems }}=614$ $\mathrm{nm})$. 

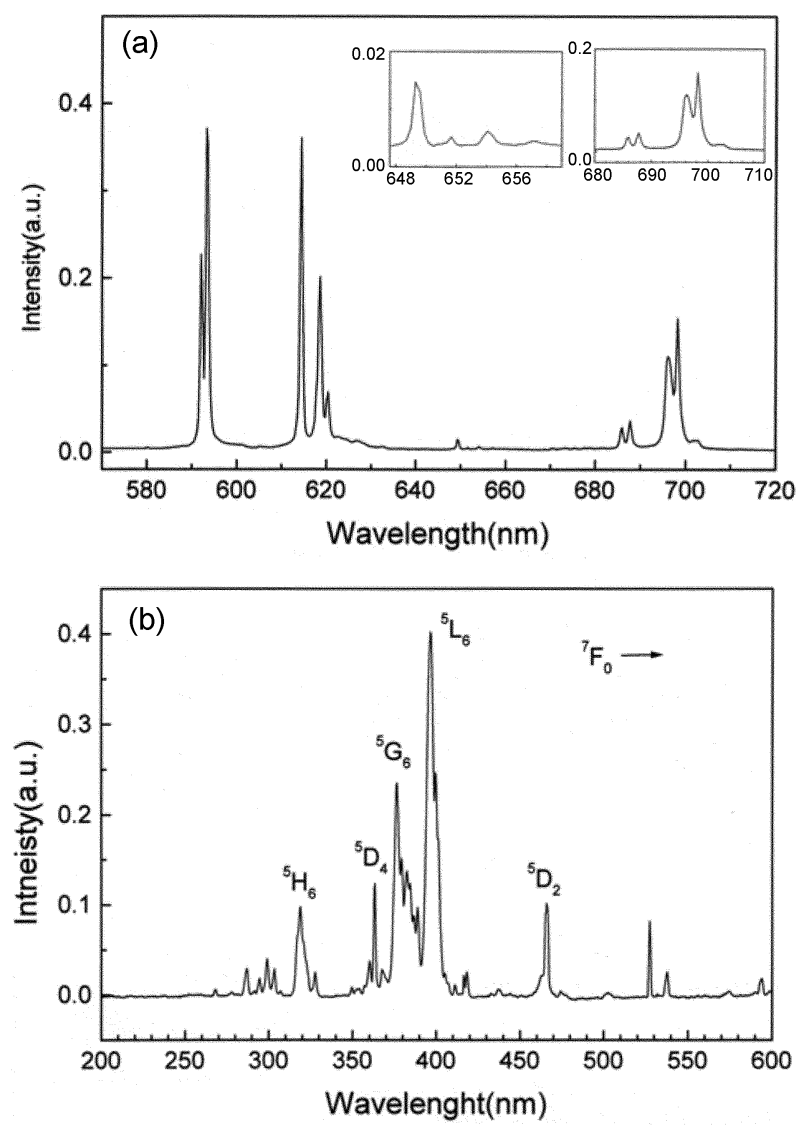

Figure 3. PL (a) and excitation (b) spectra of $\left[\mathrm{Eu}(\mathrm{ODA})_{3}\right]^{3-}$ crystals at $10 \mathrm{~K}$ : (a) $\lambda_{e x c}=325 \mathrm{~nm}$ laser and (b) $\lambda_{\text {ems }}=614 \mathrm{~nm}$ ).

$\mathrm{D}_{3 \mathrm{~h}}$ symmetry to the $\mathrm{D}_{3}$ or $\mathrm{C}_{3}$ symmetry.

As shown in Figures 2(a) and 3(a), the PL spectra of the $\mathrm{Eu}(\mathrm{III})$ complexes are dominated by well-separated lines in the wavelength region of $570-720 \mathrm{~nm}$, arising mostly from the ${ }^{5} \mathrm{D}_{0} \rightarrow{ }^{7} \mathrm{~F}_{\mathrm{J}}(\mathrm{J}=0,1,2,3,4)$ transitions of $\mathrm{Eu}(\mathrm{III})$. The most strikingly difference between PL spectra of two complexes can be found in the number of band splitting and the intensity, owing to the different site-symmetries. Selection rules for the ${ }^{5} \mathrm{D}_{0} \rightarrow{ }^{7} \mathrm{~F}_{\mathrm{J}}(J=0,1,2,3,4)$ transitions of $\mathrm{Eu}(\mathrm{III})$ under the $\mathrm{C}_{2}, \mathrm{D}_{3}$ and $\mathrm{C}_{3}$ symmetries are summarized in
Table 1. The ${ }^{5} \mathrm{D}_{0} \rightarrow{ }^{7} \mathrm{~F}_{0}$ transition is in principle forbidden, but may gain intensity through $\mathrm{J}$ mixing due to the crystalfield potential with low symmetry. For $\left[\mathrm{Eu}(\mathrm{ODA})_{3}\right]^{3-}$, this transition appeared as a trace at $580 \mathrm{~nm}$. For [Eu(ODA) (Phen) $\left.4 \mathrm{H}_{2} \mathrm{O}\right]^{+}$, the intensity of the 580 -nm band increased to a certain extent. For most of $\mathrm{Eu}(\mathrm{III})$ complexes, the characteristic feature has been found in the ${ }^{5} \mathrm{D}_{0} \rightarrow{ }^{7} \mathrm{~F}_{1}$ and ${ }^{7} \mathrm{~F}_{2}$ transitions, appearing in the $585-600 \mathrm{~nm}$ and the $605-630$ $\mathrm{nm}$ regions, respectively. Unlike other ${ }^{5} \mathrm{D}_{0} \rightarrow{ }^{7} \mathrm{~F}_{\mathrm{J}}$ transitions, the ${ }^{5} \mathrm{D}_{0} \rightarrow{ }^{7} \mathrm{~F}_{1}$ transition is allowed by the magnetic dipole moment. Therefore, this transition well reflects the site symmetry of the Eu(III) ion in the number of the lines and its intensity is almost independent of the environment with moderate intensity. Significantly, the intensity of the ${ }^{5} \mathrm{D}_{0} \rightarrow$ ${ }^{7} F_{2}$ transition has been observed to be very sensitive to the ligand environment, if the site symmetry of the ion is low. For hexahydrated europium chloride, the intensity of the ${ }^{5} \mathrm{D}_{0} \rightarrow{ }^{7} \mathrm{~F}_{2}$ transition is very low, compared with that of the ${ }^{5} \mathrm{D}_{0} \rightarrow{ }^{7} \mathrm{~F}_{1}$ transition. For the $\left[\mathrm{Eu}(\mathrm{ODA})_{3}\right]^{3-}$ complex, the intensity of the ${ }^{5} \mathrm{D}_{0} \rightarrow{ }^{7} \mathrm{~F}_{2}$ transition increases with complexing with ODA and its intensity is comparable with that of the ${ }^{5} \mathrm{D}_{0} \rightarrow{ }^{7} \mathrm{~F}_{1}$ transition. For [Eu(ODA)(Phen) $\left.\cdot 4 \mathrm{H}_{2} \mathrm{O}\right]^{+}$, the intensity of the ${ }^{5} \mathrm{D}_{0} \rightarrow{ }^{7} \mathrm{~F}_{2}$ transition is strongly enhanced to be more than four times as strong as that of the ${ }^{5} \mathrm{D}_{0} \rightarrow{ }^{7} \mathrm{~F}_{1}$ transition. The ${ }^{5} \mathrm{D}_{0} \rightarrow{ }^{7} \mathrm{~F}_{2}$ transition of Eu(III) in the mixed ODA and phen complex can be labeled as hypersensitivity. The ${ }^{5} \mathrm{D}_{0} \rightarrow$ ${ }^{7} \mathrm{~F}_{3}$ transition can be allowed by an electric dipole moment, depending on the site symmetry. For most of Eu(III) complexes, however, the intensity of this transition has been observed to be very weak. The effect of the site symmetry of Eu(III) on the intensity has been rarely revealed in the ${ }^{5} \mathrm{D}_{0} \rightarrow{ }^{7} \mathrm{~F}_{3}$ transition. For [Eu(ODA)(Phen) $\left.4 \mathrm{H}_{2} \mathrm{O}\right]^{+}$, the ${ }^{5} \mathrm{D}_{0} \rightarrow{ }^{7} \mathrm{~F}_{4}$ transition produced the well-separated 7 luminescence lines as expected under the $\mathrm{C}_{2 \mathrm{v}}$ crystal-field potential. For $\left[\mathrm{Eu}(\mathrm{ODA})_{3}\right]^{3-}$, the four characteristic lines were observed with two tiny bands at the low-energy shoulder as shown in the extended scale in Figure 3(a). The ${ }^{5} \mathrm{D}_{0} \rightarrow{ }^{7} \mathrm{~F}_{4}$ transition produces the four lines under the $\mathrm{D}_{3}$ potential and the six lines under the $\mathrm{C}_{3}$ potential. The two weak bands at the low-energy shoulder can be attributed to the transitions from the $A_{1}$ emitting level to the two $A_{1}$ sublevels of the ${ }^{7} F_{4}$ state under the $D_{3}$

Table 1. Selection rules for ${ }^{5} \mathrm{D}_{0} \rightarrow{ }^{7} \mathrm{~F}_{\mathrm{J}}$ transitions of the Eu(III) ion in $\mathrm{C}_{2 \mathrm{v}}, \mathrm{D}_{3}$ and $\mathrm{C}_{3}$ point groups of site-symmetry $(\mathrm{ED}=$ electric dipole, $\mathrm{MD}=$ magnetic dipole and + denotes allowed transition)

\begin{tabular}{|c|c|c|c|c|c|c|c|c|c|c|c|c|c|c|c|}
\hline \multirow{2}{*}{$\frac{\text { Site }}{\text { Symmetry }}$} & \multicolumn{3}{|c|}{$\mathbf{J}=0$} & \multicolumn{3}{|c|}{$\mathrm{J}=1$} & \multicolumn{3}{|c|}{$\mathrm{J}=2$} & \multicolumn{3}{|c|}{$\mathrm{J}=3$} & \multicolumn{3}{|c|}{$\mathrm{J}=4$} \\
\hline & $\Gamma_{\mathrm{J}}$ & ED & MD & $\Gamma_{J}$ & ED & MD & $\Gamma_{\mathrm{J}}$ & ED & MD & $\Gamma_{\mathrm{J}}$ & ED & MD & $\Gamma_{\mathrm{J}}$ & ED & MD \\
\hline \multirow[t]{4}{*}{$\mathrm{C}_{2 \mathrm{v}}$} & $A_{1}$ & + & - & $\mathrm{A}_{2}$ & - & + & $2 \mathrm{~A}_{1}$ & + & - & $\mathrm{A}_{1}$ & + & - & $3 \mathrm{~A}_{1}$ & + & - \\
\hline & & & & $\mathrm{B}_{1}$ & + & + & $\mathrm{A}_{2}$ & - & + & $2 \mathrm{~A}_{2}$ & - & + & $2 \mathrm{~A}_{2}$ & - & + \\
\hline & & & & $\mathrm{B}_{2}$ & + & + & $\mathrm{B}_{1}$ & + & + & $\mathrm{B}_{1}$ & + & + & $2 \mathrm{~B}_{1}$ & + & + \\
\hline & & & & & & & $\mathrm{B}_{2}$ & + & + & $\mathrm{B}_{2}$ & + & + & $2 \mathrm{~B}_{2}$ & + & + \\
\hline \multirow[t]{3}{*}{$\mathrm{D}_{3}$} & $\mathrm{~A}_{1}$ & - & - & $\mathrm{A}_{2}$ & + & + & $A_{1}$ & - & - & $\mathrm{A}_{1}$ & - & - & $2 \mathrm{~A}_{1}$ & - & - \\
\hline & & & & $\mathrm{E}$ & + & + & $2 \mathrm{E}$ & + & + & $2 \mathrm{~A}_{2}$ & + & + & $\mathrm{A}_{2}$ & + & + \\
\hline & & & & & & & & & & $2 \mathrm{E}$ & + & + & $3 \mathrm{E}$ & + & + \\
\hline \multirow[t]{2}{*}{$\mathrm{C}_{3}$} & A & + & + & A & + & + & A & + & + & $3 \mathrm{~A}$ & + & + & $3 \mathrm{~A}$ & + & + \\
\hline & & & & $\mathrm{E}$ & + & + & $2 \mathrm{E}$ & + & + & $2 \mathrm{E}$ & + & + & $3 \mathrm{E}$ & + & + \\
\hline
\end{tabular}


potential, partially allowed by the magnetic dipole.

The comparison between $\left[\mathrm{Eu}(\mathrm{ODA})(\mathrm{Phen}) \cdot 4 \mathrm{H}_{2} \mathrm{O}\right]^{+}$and $\left[\mathrm{Eu}(\mathrm{ODA})_{3}\right]^{3-}$ complexes can be found in the excitation spectrum. As shown in Figures 2(b) and 3(b), for [Eu(ODA) (Phen) $\left.\cdot 4 \mathrm{H}_{2} \mathrm{O}\right]^{+}$, a broad band, peaking at $345 \mathrm{~nm}$, which was not found in the excitation spectrum of $\left[\mathrm{Eu}(\mathrm{ODA})_{3}\right]^{3-}$ crystals, can be attributed to the energy transfer from phen to the $\mathrm{Eu}(\mathrm{III})$. For most of $\mathrm{Eu}(\mathrm{III})$ complexes, the ${ }^{7} \mathrm{~F}_{0} \rightarrow{ }^{5} \mathrm{~L}_{6}$ transition, peaking at $395 \mathrm{~nm}$, is most strongest among the transitions in the UV-visible region and its intensity is almost insensitive to the ligand environment. Contrary, the ${ }^{7} \mathrm{~F}_{0} \rightarrow$ ${ }^{5} \mathrm{D}_{2}$ transition is mostly weak but its intensity is sensitive to the ligand environment, since it satisfies the selection rule, $\Delta \mathrm{J}= \pm 2$, for hypersensitivity. The ratio of the intensity of this transition to that of the ${ }^{7} \mathrm{~F}_{0} \rightarrow{ }^{5} \mathrm{~L}_{6}$ transition is ca. 0.7 for $\left[\mathrm{Eu}(\mathrm{ODA})(\mathrm{Phen}) \cdot 4 \mathrm{H}_{2} \mathrm{O}\right]^{+}$and 0.25 for $\left[\mathrm{Eu}(\mathrm{ODA})_{3}\right]^{3-}$.

As shown in Figures 4(a) and 5(a), the Tb(III) complexes produced very typical band features, originating from the transitions from the ${ }^{5} \mathrm{D}_{4}$ state to the ${ }^{7} \mathrm{~F}_{6,5,4,3}$ states, peaking at 489, 545, 582 and $621 \mathrm{~nm}$, respectively. In addition, three ${ }^{5} \mathrm{D}_{4} \rightarrow{ }^{7} \mathrm{~F}_{2,1,0}$ transitions, peaking at 649,668 and $679 \mathrm{~nm}$, respectively, are very weak, as shown in the extended scale in Figures 4(a) and 5(a). For most of Tb(III) complexes, the ${ }^{5} \mathrm{D}_{4} \rightarrow{ }^{7} \mathrm{~F}_{6,4,3}$ transitions have been observed to show moderate sensitivity to the ligand environment and the ${ }^{5} \mathrm{D}_{4}$ $\rightarrow{ }^{7} \mathrm{~F}_{5}$ transition has been observed to produce the most
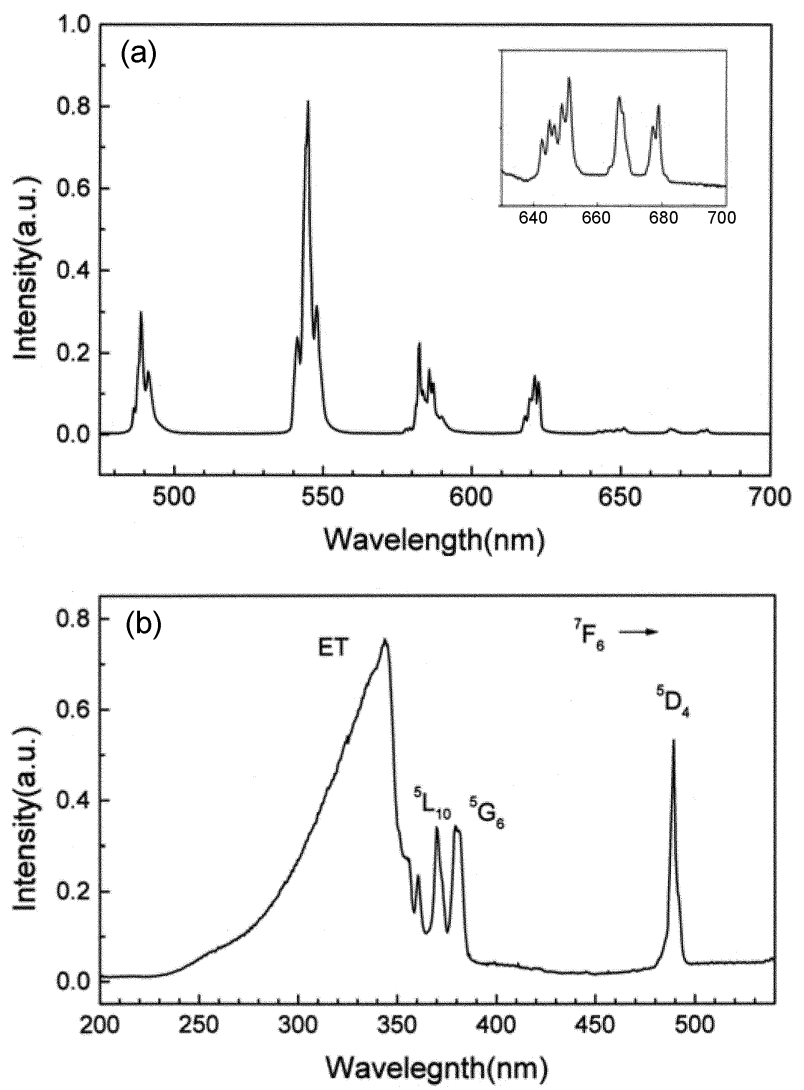

Figure 4. PL (a) and excitation (b) spectra of [Tb(ODA)(Phen). $\left.4 \mathrm{H}_{2} \mathrm{O}\right]^{+}$crystals at $10 \mathrm{~K}$ : (a) $\lambda_{\text {exc }}=325 \mathrm{~nm}$ laser and (b) $\lambda_{\text {ems }}=544$ $\mathrm{nm})$.
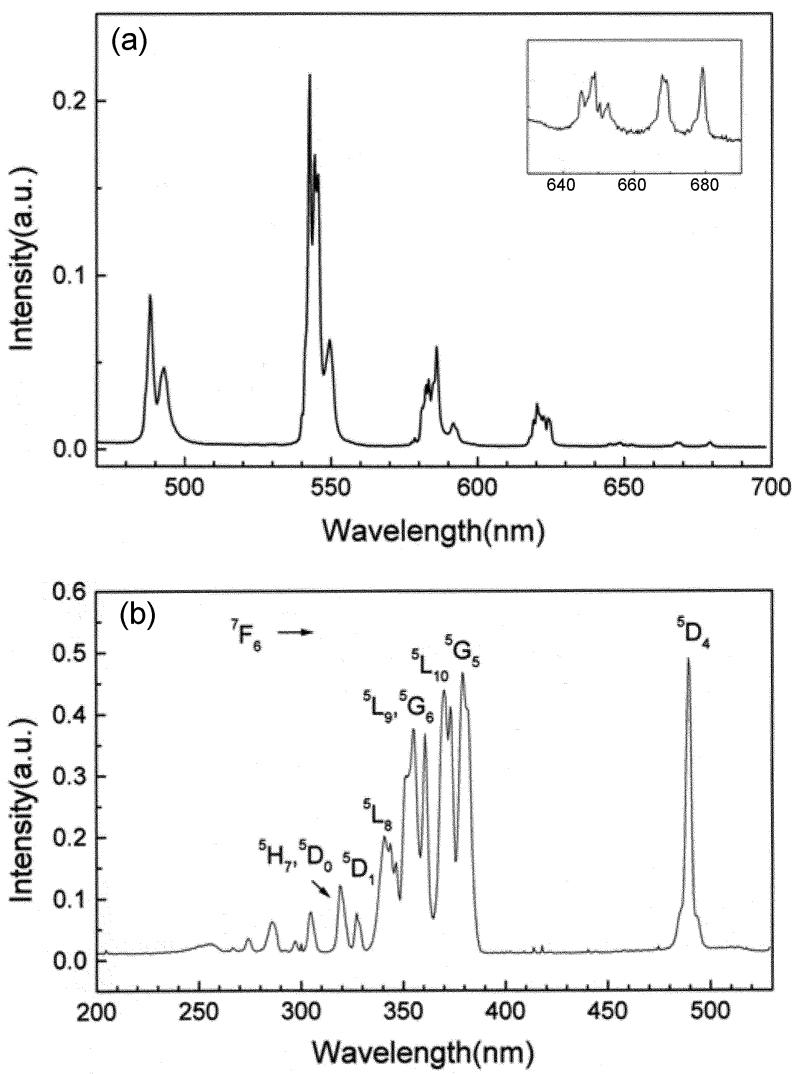

Figure 5. PL (a) and excitation (b) spectra of $\left[\mathrm{Tb}(\mathrm{ODA})_{3}\right]^{3-}$ crystals at $10 \mathrm{~K}$ : (a) $\lambda_{\text {exc }}=325 \mathrm{~nm}$ laser and (b) $\lambda_{\text {ems }}=544 \mathrm{~nm}$ ).

intense luminescence. The band positions of the PL of $\left[\mathrm{Tb}(\mathrm{ODA})(\text { phen }) \cdot 4 \mathrm{H}_{2} \mathrm{O}\right]^{+}$are almost identical to those of $[\mathrm{Tb}(\mathrm{ODA})]^{3-}$, but the band splitting of the two complexes differs slightly. Significant differences between these two complexes can be found in the excitation spectrum. As seen in $\left[\mathrm{Eu}(\mathrm{ODA})(\text { phen }) \cdot 4 \mathrm{H}_{2} \mathrm{O}\right]^{+}$, for $\left[\mathrm{Tb}(\mathrm{ODA})(\text { phen }) \cdot 4 \mathrm{H}_{2} \mathrm{O}\right]^{+}$, a strong ligand-to-metal energy transfer band appeared at 344 $\mathrm{nm}$. As shown in Figure 4(b), the intensity of the energytransfer band is stronger than that of the 489-nm metalcentered excitation band.

Energy-level Simulation. The crystal structure and the luminescence line-splitting show that the most appropriate site symmetries of the $\mathrm{Eu}(\mathrm{III})$ and $\mathrm{Tb}(\mathrm{III})$ ions are $\mathrm{C}_{2 \mathrm{v}}$ for the mixed ODA and phen complexes and $\mathrm{D}_{3}$ for the homoleptic ODA complexes. Following the formalism used by Wybourne, ${ }^{10}$ the crystal-field Hamiltonian (CFH) can be expressed as a sum of the products between the CF parameters, $B_{q}^{k}$ and the spherical tensor operators $C_{q}^{(k)}$. The final form of the CFH is as follows:

$$
\begin{aligned}
H_{C F} & \left(C_{2 v}\right)=B_{0}^{2} C_{0}^{(2)}+B_{2}^{2}\left(C_{2}^{(2)}+C_{-2}^{(2)}\right) \\
& +B_{0}^{4} C_{0}^{(4)}+B_{2}^{4}\left(C_{2}^{(4)}+C_{-2}^{(4)}\right)+B_{4}^{4}\left(C_{4}^{(4)}+C_{-4}^{(4)}\right) \\
& +B_{0}^{6} C_{0}^{(6)}+B_{2}^{6}\left(C_{2}^{(6)}+C_{-2}^{(6)}\right)+B_{4}^{6}\left(C_{4}^{(6)}+C_{-4}^{(6)}\right) \\
& +B_{6}^{6}\left(C_{6}^{(6)}+C_{-6}^{(6)}\right)
\end{aligned}
$$

and

$$
H_{C F}\left(D_{3}, C_{3}\right)=B_{0}^{2} C_{0}^{(2)}+B_{0}^{4} C_{0}^{(4)}+B_{3}^{4}\left(C_{3}^{(4)}-C_{-3}^{(4)}\right)
$$




$$
+B_{0}^{6} C_{0}^{(6)}+B_{3}^{6}\left(C_{3}^{(6)}-C_{-3}^{(6)}\right)+B_{6}^{6}\left(C_{6}^{(6)}-C_{-6}^{(6)}\right)
$$

Assuming that the CFH would not cause mixing of the ${ }^{7} \mathrm{~F}_{\mathrm{J}}$ and other electronic states due to the large energy-gap, the matrix elements in the $\mathrm{CFH}$ are approximations of the problems between the $\left|f^{N}{ }^{7} \mathrm{~F} ; J J_{z}\right\rangle$ and $\left|f^{N}{ }^{7} \mathrm{~F} ; J^{\prime} J_{z}\right\rangle$ states.

For Eu(III) ion, the number of the observed bands in the ${ }^{5} \mathrm{D}_{0} \rightarrow{ }^{7} \mathrm{~F}_{\mathrm{J}}$ transitions are determined by electric-dipole $(\mathrm{J}=$ 2, 3 and 4) or magnetic-dipole ( $\mathrm{J}=1)$ selection rules, as listed in Table 1. For $\mathrm{Tb}(\mathrm{III})$ ion, however, the theoretical analysis of the observed luminescence spectrum is very complicated, owing to the multiplicity of the ${ }^{5} \mathrm{D}_{4}$ state as the emitting level. For $\left[\mathrm{Tb}(\mathrm{ODA})(\text { phen }) \cdot 4 \mathrm{H}_{2} \mathrm{O}\right]^{+}$, as seen in the extended scale in Figure $4(\mathrm{a})$, the ${ }^{5} \mathrm{D}_{4} \rightarrow{ }^{7} \mathrm{~F}_{0}$ transition consists of at least two Gaussian bands, peaking at 677.3 and $678.9 \mathrm{~nm}$, respectively. For $\left[\mathrm{Tb}(\mathrm{ODA})_{3}\right]^{3-}$, the $679.3 \mathrm{~nm}$ band, responsible for the ${ }^{5} \mathrm{D}_{4} \rightarrow{ }^{4} \mathrm{~F}_{0}$ transition, accompanies a shoulder at high-energy side. It indicates that the observed luminescence lines are associated with at least two sublevels of the ${ }^{5} \mathrm{D}_{4}$ state. Using the irreducible representations, we shall classify the split sublevels and identify the observed luminescence lines. Under the $C_{2 v}$ symmetry, the $A_{1} \leftrightarrow B_{1}$, $A_{1} \leftrightarrow B_{2}, A_{2} \leftrightarrow B_{1}$ and $A_{2} \leftrightarrow B_{2}$ transitions are allowed by electric-dipole and magnetic-dipole momenta, while the $\mathrm{A}_{1}$ $\leftrightarrow \mathrm{A}_{1}, \mathrm{~A}_{2} \leftrightarrow \mathrm{A}_{2}, \mathrm{~B}_{1} \leftrightarrow \mathrm{B}_{1}$ and $\mathrm{B}_{2} \leftrightarrow \mathrm{B}_{2}$ transitions are allowed by only the electric-dipole moment and the $A_{1} \leftrightarrow$ $A_{2}$ and $B_{1} \leftrightarrow B_{2}$ transitions are allowed by only the magnetic-dipole moment. The selection rule of $\Delta \mathrm{J}= \pm 1$ may allow the ${ }^{5} \mathrm{D}_{4} \rightarrow{ }^{7} \mathrm{~F}_{3,5}$ transitions to have additional magnetic dipole character. Under the $\mathrm{D}_{3}$ symmetry, the $\mathrm{A}_{1} \leftrightarrow \mathrm{E}, \mathrm{A}_{2} \leftrightarrow$ $\mathrm{E}$ and $\mathrm{E} \leftrightarrow \mathrm{E}$ transitions are allowed by electric-dipole and magnetic-dipole momenta, while the $\mathrm{A}_{1} \leftrightarrow \mathrm{A}_{2}$ transition is allowed by only the electric-dipole moment and the $A_{1} \leftrightarrow$ $A_{1}$ and $A_{2} \leftrightarrow A_{2}$ transitions are allowed by only the magnetic-dipole moment. Taking into account these selection rules, the experimental energy level schemes of the $\mathrm{Tb}(\mathrm{III})$ ion in the complex were fitted by simulating the

Table 2. The crystal-field parameters* for $[\mathrm{Eu}(\mathrm{ODA})(\mathrm{phen})$. $\left.4 \mathrm{H}_{2} \mathrm{O}\right]^{+},\left[\mathrm{Tb}(\mathrm{ODA})(\text { phen }) \cdot 4 \mathrm{H}_{2} \mathrm{O}\right]^{+},\left[\mathrm{Eu}(\mathrm{ODA})_{3}\right]^{3-}$ and $\left[\mathrm{Tb}(\mathrm{ODA})_{3}\right]^{3-}$ complexes. All values are in $\mathrm{cm}^{-1}$

\begin{tabular}{ccccc}
\hline Parameter & $\mathrm{Eu} / \mathrm{ODA} / \mathrm{phen}$ & $\mathrm{Eu} / \mathrm{ODA}$ & $\mathrm{Tb} / \mathrm{ODA} / \mathrm{phen}$ & $\mathrm{Tb} / \mathrm{ODA}$ \\
\hline$B_{0}^{2}$ & $-186(44)$ & $176(88)$ & $-214(53)$ & $153(88)$ \\
$B_{2}^{2}$ & $-113(25)$ & - & $22(72)$ & - \\
$B_{0}^{4}$ & $-309(64)$ & $620(131)$ & $-714(97)$ & $1043(116)$ \\
$B_{2}^{4}$ & $-476(50)$ & - & $-433(64)$ & - \\
$B_{3}^{4}$ & - & $590(104)$ & - & $431(86)$ \\
$B_{4}^{4}$ & $110(48)$ & - & $616(82)$ & - \\
$B_{0}^{6}$ & $1212(62)$ & $-836(134)$ & $463(95)$ & $-725(100)$ \\
$B_{2}^{6}$ & $281(57)$ & - & $360(81)$ & - \\
$B_{3}^{6}$ & - & $-466(126)$ & - & $-892(103)$ \\
$B_{4}^{6}$ & $-498(60)$ & - & $-227(119)$ & - \\
$B_{6}^{6}$ & $305(73)$ & $690(102)$ & $67(82)$ & $311(83)$ \\
$\mathrm{S}_{\mathrm{cf}}$ & $291(31)$ & $309(58)$ & $281(48)$ & $339(58)$ \\
$\sigma$ & 9.7 & 22.6 & 10.0 & 13.3 \\
\hline
\end{tabular}

${ }^{*}$ Values in parentheses represent uncertainties.
Table 3. Energy-level schemes of Eu(III) ions in [Eu(ODA)(phen). $\left.4 \mathrm{H}_{2} \mathrm{O}\right]^{+}$and $\left[\mathrm{Eu}(\mathrm{ODA})_{3}\right]^{3-}$ complexes. The baricenter of each state is given in parenthesis

\begin{tabular}{|c|c|c|c|c|c|}
\hline Level & cal. & exp. & Level & cal. & exp. \\
\hline${ }^{7} \mathrm{~F}_{0}$ & (0) & & & (0) & \\
\hline $\mathrm{A}_{1}$ & 0 & 0 & $A_{1}$ & 0 & 0 \\
\hline${ }^{7} F_{1}$ & (380) & & & (354) & \\
\hline $\mathrm{A}_{2}$ & 341 & 339 & E & 334 & 339 \\
\hline $\mathrm{B}_{2}$ & 368 & 365 & $\mathrm{~A}_{2}$ & 388 & 381 \\
\hline $\mathrm{B}_{1}$ & 418 & 424 & & & \\
\hline${ }^{7} F_{2}$ & (1072) & & & (1035) & \\
\hline $\mathrm{A}_{1}$ & 1003 & 995 & $\mathrm{E}$ & 961 & 953 \\
\hline $\mathrm{B}_{1}$ & 1023 & 1035 & $\mathrm{E}$ & 1061 & 1063 \\
\hline $\mathrm{B}_{2}$ & 1067 & 1074 & $A_{1}$ & 1102 & 1110 \\
\hline $\mathrm{A}_{2}$ & 1100 & - & & & \\
\hline$A_{1}$ & 1132 & 1136 & & & \\
\hline${ }^{7} \mathrm{~F}_{3}$ & (1882) & & & (1920) & \\
\hline $\mathrm{B}_{1}$ & 1802 & - & $\mathrm{A}_{2}$ & 1867 & 1828 \\
\hline $\mathrm{A}_{2}$ & 1839 & - & $\mathrm{E}$ & 1877 & 1884 \\
\hline $\mathrm{B}_{2}$ & 1846 & - & $A_{1}$ & 1890 & - \\
\hline $\mathrm{B}_{1}$ & 1864 & 1868 & $\mathrm{E}$ & 1944 & 1940 \\
\hline$A_{1}$ & 1908 & - & $\mathrm{A}_{2}$ & 1983 & 2016 \\
\hline $\mathrm{B}_{2}$ & 1908 & 1910 & & & \\
\hline $\mathrm{A}_{2}$ & 1917 & - & & & \\
\hline${ }^{7} \mathrm{~F}_{4}$ & (2889) & & & $(2815)$ & \\
\hline $\mathrm{A}_{2}$ & 2705 & - & $\mathrm{A}_{2}$ & 2666 & 2651 \\
\hline $\mathrm{B}_{1}$ & 2716 & 2709 & $\mathrm{E}$ & 2684 & 2689 \\
\hline $\mathrm{A}_{2}$ & 2820 & - & E & 2845 & 2863 \\
\hline $\mathrm{B}_{2}$ & 2833 & 2828 & $\mathrm{E}$ & 2883 & 2906 \\
\hline $\mathrm{B}_{1}$ & 2850 & 2865 & $A_{1}$ & 2974 & 2979 \\
\hline $\mathrm{A}_{1}$ & 2916 & 2920 & $\mathrm{~A}_{1}$ & 3031 & 2998 \\
\hline $\mathrm{B}_{2}$ & 2954 & 2945 & & & \\
\hline $\mathrm{A}_{1}$ & 3001 & 3005 & & & \\
\hline $\mathrm{A}_{1}$ & 3095 & 3090 & & & \\
\hline
\end{tabular}

observed luminescence lines. The sets of the CF parameters obtained by the best fit are listed in Table 2 . The calculated and observed energy levels of the $\mathrm{Eu}(\mathrm{III})$ and $\mathrm{Tb}$ (III) ions in the complexes are also listed in Tables 3 and 4. Except the case of $\left[\mathrm{Eu}(\mathrm{ODA})_{3}\right]^{3-}$, the fits of the energy-level schemes observed within the ${ }^{5} \mathrm{D}_{0} \rightarrow{ }^{7} \mathrm{~F}_{\mathrm{J}}(\mathrm{J}=0-4)$ in $\left[\mathrm{Eu}(\mathrm{ODA})(\text { phen }) \cdot 4 \mathrm{H}_{2} \mathrm{O}\right]^{+}$, and the ${ }^{5} \mathrm{D}_{4} \rightarrow{ }^{7} \mathrm{~F}_{\mathrm{J}}(\mathrm{J}=6-0)$ in $\left[\mathrm{Tb}(\mathrm{ODA})(\text { phen }) \cdot 4 \mathrm{H}_{2} \mathrm{O}\right]^{+}$and $\left[\mathrm{Tb}(\mathrm{ODA})_{3}\right]^{3-}$ are reasonably good: the root-mean-square ( $\mathrm{s}$ ) deviations for the three complexes are $9.7,10.3$ and $13.3 \mathrm{~cm}^{-1}$, respectively. The large deviation in the case of $\left[\mathrm{Eu}(\mathrm{ODA})_{3}\right]^{3-}$ arises from the weak ${ }^{5} \mathrm{D}_{0} \rightarrow{ }^{7} \mathrm{~F}_{3}$ transition.

The crystal-field strength parameter, $S_{c f}$, defined in terms of the $B_{q}^{k}$ parameters by:

$$
\begin{gathered}
S_{c f}=\left\{\frac{1}{3} \sum_{k}\left(S_{c f}^{k}\right)^{2}\right\}^{1 / 2} \\
S_{c f}^{k}=\left[\frac{1}{2 k+1}\left\{\left(B_{0}^{k}\right)^{2}+2 \sum_{q>0}\left(B_{q}^{k}\right)^{2}\right\}\right]^{1 / 2}
\end{gathered}
$$


Table 4. Energy-level schemes of Tb(III) ions in $[\mathrm{Tb}(\mathrm{ODA})($ phen). $\left.4 \mathrm{H}_{2} \mathrm{O}\right]^{+}$and $\left[\mathrm{Tb}(\mathrm{ODA})_{3}\right]^{3-}$ complexes. The baricenter of each state is given in parenthesis

\begin{tabular}{|c|c|c|c|c|c|}
\hline Level & cal. & exp. & Level & cal. & exp. \\
\hline${ }^{7} \mathrm{~F}_{6}$ & (133) & & & (130) & \\
\hline $\mathrm{B}_{1}$ & 0 & 0 & $A_{1}$ & 0 & 0 \\
\hline $\mathrm{A}_{1}$ & 2 & 0 & $\mathrm{E}$ & 38 & - \\
\hline $\mathrm{B}_{2}$ & 16 & - & $\mathrm{A}_{2}$ & 44 & - \\
\hline $\mathrm{A}_{2}$ & 23 & - & $\mathrm{E}$ & 54 & - \\
\hline $\mathrm{B}_{1}$ & 75 & - & $A_{1}$ & 60 & - \\
\hline$A_{1}$ & 87 & - & $\mathrm{A}_{2}$ & 171 & - \\
\hline $\mathrm{B}_{2}$ & 109 & 100 & $A_{1}$ & 192 & 193 \\
\hline $\mathrm{A}_{2}$ & 145 & - & $\mathrm{E}$ & 225 & - \\
\hline$A_{1}$ & 150 & - & $\mathrm{E}$ & 245 & - \\
\hline $\mathrm{A}_{2}$ & 241 & & & & \\
\hline $\mathrm{B}_{1}$ & 243 & - & & & \\
\hline$A_{1}, B_{2}$ & 252 & - & & & \\
\hline $\mathrm{A}_{2}$ & 256 & - & & & \\
\hline${ }^{7} \mathrm{~F}_{5}$ & (2136) & & & (2191) & \\
\hline $\mathrm{B}_{2}$ & 1983 & 1982 & $\mathrm{E}$ & 2053 & 2058 \\
\hline $\mathrm{B}_{1}$ & 2020 & - & $\mathrm{A}_{2}$ & 2126 & 2117 \\
\hline $\mathrm{A}_{2}$ & 2090 & - & $\mathrm{E}$ & 2141 & 2156 \\
\hline$A_{1}$ & 2101 & 2103 & $A_{1}$ & 2149 & - \\
\hline $\mathrm{B}_{2}$ & 2138 & - & $\mathrm{E}$ & 2174 & - \\
\hline $\mathrm{A}_{2}$ & 2163 & - & $\mathrm{A}_{2}$ & 2291 & 2281 \\
\hline $\mathrm{B}_{1}$ & 2165 & - & $\mathrm{E}$ & 2400 & - \\
\hline $\mathrm{B}_{2}$ & 2205 & 2202 & & & \\
\hline$A_{1}$ & 2212 & - & & & \\
\hline $\mathrm{B}_{1}$ & 2217 & - & & & \\
\hline $\mathrm{A}_{2}$ & 2242 & 2243 & & & \\
\hline${ }^{7} \mathrm{~F}_{4}$ & (3310) & & & (3335) & \\
\hline $\mathrm{B}_{1}$ & 3141 & 3153 & $\mathrm{~A}_{1}$ & 3181 & 3168 \\
\hline$A_{1}$ & 3212 & 3198 & $\mathrm{E}$ & 3196 & 3194 \\
\hline $\mathrm{A}_{2}$ & 3261 & 3251 & $\mathrm{~A}_{2}$ & 3316 & - \\
\hline$A_{1}$ & 3278 & 3286 & $\mathrm{E}$ & 3371 & 3341 \\
\hline $\mathrm{A}_{2}$ & 3321 & 3321 & $\mathrm{E}$ & 3422 & 3416 \\
\hline $\mathrm{B}_{2}$ & 3339 & 3348 & $A_{1}$ & 3569 & 3584 \\
\hline $\mathrm{B}_{1}$ & 3362 & 3382 & & & \\
\hline $\mathrm{B}_{2}$ & 3406 & 3117 & & & \\
\hline $\mathrm{A}_{1}$ & 3503 & 3503 & & & \\
\hline${ }^{7} \mathrm{~F}_{3}$ & (4343) & & & (4375) & \\
\hline $\mathrm{B}_{2}$ & 4288 & 4271 & $\mathrm{E}$ & 4324 & 4328 \\
\hline $\mathrm{B}_{1}$ & 4311 & 4310 & $\mathrm{~A}_{2}$ & 4364 & 4358 \\
\hline $\mathrm{B}_{2}$ & 4323 & - & $A_{1}$ & 4374 & 4381 \\
\hline $\mathrm{A}_{2}$ & 4326 & - & $\mathrm{E}$ & 4411 & 4418 \\
\hline$A_{1}$ & 4342 & 4357 & $\mathrm{~A}_{2}$ & 4441 & 4463 \\
\hline $\mathrm{B}_{1}$ & 4387 & 4388 & & & \\
\hline $\mathrm{A}_{2}$ & 4401 & - & & & \\
\hline${ }^{7} \mathrm{~F}_{2}$ & (4980) & & & (5037) & \\
\hline $\mathrm{B}_{1}$ & 4889 & 4888 & $\mathrm{E}$ & 4965 & 4987 \\
\hline$A_{1}$ & 4943 & 4945 & E & 5081 & 5067 \\
\hline $\mathrm{B}_{2}$ & 4995 & 4988 & $A_{1}$ & 5158 & 5155 \\
\hline $\mathrm{A}_{2}$ & 5058 & 5042 & & & \\
\hline $\mathrm{A}_{1}$ & 5102 & 5094 & & & \\
\hline${ }^{7} \mathrm{~F}_{1}$ & (5435) & & & (5515) & \\
\hline $\mathrm{A}_{2}$ & 5397 & 5397 & $\mathrm{E}$ & 5501 & 5512 \\
\hline $\mathrm{B}_{2}$ & 5469 & 5458 & $\mathrm{~A}_{2}$ & 5547 & 5538 \\
\hline $\mathrm{B}_{1}$ & 5471 & 5478 & & & \\
\hline${ }^{7} \mathrm{~F}_{0}$ & (5721) & & & (5762) & \\
\hline$A_{1}$ & 5721 & 5721 & $\mathrm{~A}_{1}$ & 5762 & 5762 \\
\hline${ }^{5} \mathrm{D}_{4}$ & (20501) & & & (20545) & \\
\hline $\mathrm{B}_{1}$ & 20442 & 20450 & $\mathrm{~A}_{1}$ & 20487 & 20488 \\
\hline$A_{1}$ & 20483 & 20486 & $\mathrm{~A}_{2}$ & 20494 & 20488 \\
\hline $\mathrm{B}_{2}$ & 20483 & 20486 & $\mathrm{E}$ & 20522 & 20526 \\
\hline $\mathrm{A}_{2}$ & 20500 & - & $\mathrm{E}$ & 20548 & - \\
\hline $\mathrm{A}_{1}$ & 20518 & - & $\mathrm{E}$ & 20590 & - \\
\hline$A_{2}, A_{1}$ & 20543 & - & & 20603 & - \\
\hline $\mathrm{B}_{1}$ & 20551 & - & & & \\
\hline
\end{tabular}

can provide the relative strength of the crystal-field interaction of a particular rare earth ion with a particular host crystal. ${ }^{11}$ As listed in Table 2, we obtained $S_{c f}=291 \mathrm{~cm}^{-1}$ for $\left[\mathrm{Eu}(\mathrm{ODA})(\text { phen }) \cdot 4 \mathrm{H}_{2} \mathrm{O}\right]^{+}$and $S_{c f}=309 \mathrm{~cm}^{-1}$ for $\left[\mathrm{Eu}(\mathrm{ODA})_{3}\right]^{3-}$. The corresponding strength parameter is $S_{c f}=281 \mathrm{~cm}^{-1}$ for $\left[\mathrm{Tb}(\mathrm{ODA})(\text { phen }) \cdot 4 \mathrm{H}_{2} \mathrm{O}\right]^{+}$and $S_{c f}=339 \mathrm{~cm}^{-1}$ for $\left[\mathrm{Tb}(\mathrm{ODA})_{3}\right]^{3-}$. These results indicate that the overall crystal-field interaction in the ODA complex is slightly stronger than that in the mixed ODA and phen complex.

Quantum Yield and Lifetime. Previously, ${ }^{8}$ the quantum yield and the decay time of the sensitized and non-sensitized luminescence of the complexes were determined in crystalline state. In this work, the PL quantum yield the complexes in crystalline and solution state were also precisely determined at room temperature on a $325-\mathrm{nm}$ excitation and compared with the quantum yields of the sensitized and the nonsensitized luminescence in Table 5. For [Eu(ODA)(phen). $\left.4 \mathrm{H}_{2} \mathrm{O}\right]^{+}$and $\left[\mathrm{Tb}(\mathrm{ODA})(\text { phen }) \cdot 4 \mathrm{H}_{2} \mathrm{O}\right]^{+}, 325-\mathrm{nm}$ excitation produces sensitized luminescence via the energy transfer from phen to the rare earth metal ions, while for $\left[\mathrm{Eu}(\mathrm{ODA})_{3}\right]^{3-}$ and $\left[\mathrm{Tb}(\mathrm{ODA})_{3}\right]^{3-}$, it produces non-sensitized luminescence via the metal-centered excitation, i.e., the ${ }^{7} \mathrm{~F}_{0} \rightarrow{ }^{5} \mathrm{H}_{6}$ transition of the $\mathrm{Eu}(\mathrm{III})$ ion and the ${ }^{7} \mathrm{~F}_{6} \rightarrow{ }^{5} \mathrm{D}_{1}$ transitions of the $\mathrm{Tb}(\mathrm{III})$ ion. As listed in Table 5, the PL quantum yields of $\left[\mathrm{Eu}(\mathrm{ODA})_{3}\right]^{3-}$ and $\left[\mathrm{Tb}(\mathrm{ODA})_{3}\right]^{3-}$ in crystalline state are only 1.1 and $1.3 \%$, respectively. For [Eu(ODA)(phen). $\left.4 \mathrm{H}_{2} \mathrm{O}\right]^{+}$and $\left[\mathrm{Tb}(\mathrm{ODA})(\text { phen }) \cdot 4 \mathrm{H}_{2} \mathrm{O}\right]^{+}$complexes, the $\mathrm{PL}$ quantum yields markedly increase to 17.7 and $56.6 \%$, respectively. For $\left[\mathrm{Eu}(\mathrm{ODA})(\text { phen }) \cdot 4 \mathrm{H}_{2} \mathrm{O}\right]^{+}$, it was observed that the PL is more efficient than the normal luminescence. The Eu(III) and $\mathrm{Tb}(\mathrm{III})$ complexes with mixed ODA and

Table 5. Absolute quantum yields of PL, the sensitized and the non-sensitized luminescence, and observed decay constants of $\left[\mathrm{Eu}(\mathrm{ODA})(\text { phen }) \cdot 4 \mathrm{H}_{2} \mathrm{O}\right]^{+},\left[\mathrm{Eu}(\mathrm{ODA})_{3}\right]^{3-},\left[\mathrm{Tb}(\mathrm{ODA})(\text { phen }) \cdot 4 \mathrm{H}_{2} \mathrm{O}\right]^{+}$ and $\left[\mathrm{Tb}(\mathrm{ODA})_{3}\right]^{3-}$ complexes in crystalline and solution states

\begin{tabular}{|c|c|c|c|c|c|c|}
\hline \multirow{2}{*}{ Complex } & \multicolumn{3}{|c|}{$Q(\%)$} & \multirow{2}{*}{$\begin{array}{r}\lambda_{\text {exc }} \\
(\mathrm{nm})\end{array}$} & \multirow{2}{*}{$\begin{array}{r}\lambda_{e m s} \\
(\mathrm{~nm})\end{array}$} & \multirow{2}{*}{$\begin{array}{c}\tau \\
(\mathrm{ms})\end{array}$} \\
\hline & PL & sens. & non-sens. & & & \\
\hline \multicolumn{7}{|c|}{$\left[\mathrm{Eu}(\mathrm{ODA})(\text { phen }) \cdot 4 \mathrm{H}_{2} \mathrm{O}\right]^{+}$} \\
\hline \multirow[t]{2}{*}{ crystalline } & 17.7 & 6.6 & 2.0 & 345 & 612 & $0.27^{8}$ \\
\hline & & & & 398 & 612 & $0.28^{8}$ \\
\hline \multirow[t]{2}{*}{ solution } & 10.2 & - & - & 345 & 612 & 0.44 \\
\hline & & & & 398 & 612 & 0.43 \\
\hline \multicolumn{7}{|c|}{$\left[\mathrm{Eu}(\mathrm{ODA})_{3}\right]^{3-}$} \\
\hline crystalline & 1.1 & - & 7.1 & 398 & 614 & $1.08^{8}$ \\
\hline solution & 1.0 & - & - & 398 & 614 & 1.08 \\
\hline \multicolumn{7}{|c|}{$\left[\mathrm{Tb}(\mathrm{ODA})(\text { phen }) \cdot 4 \mathrm{H}_{2} \mathrm{O}\right]^{+}$} \\
\hline \multirow[t]{2}{*}{ crystalline } & 56.6 & 75.7 & 24.0 & 345 & 545 & $0.83^{8}$ \\
\hline & & & & 490 & 545 & $0.85^{8}$ \\
\hline \multirow[t]{2}{*}{ solution } & 11.4 & - & - & 344 & 545 & 0.22 \\
\hline & & & & 490 & 545 & 0.21 \\
\hline \multicolumn{7}{|c|}{$\left[\mathrm{Tb}(\mathrm{ODA})_{3}\right]^{3-}$} \\
\hline \multirow[t]{2}{*}{ crystalline } & 1.3 & - & 21.0 & 376 & 545 & $2.87^{8}$ \\
\hline & & & & 490 & 545 & $2.88^{8}$ \\
\hline \multirow[t]{2}{*}{ solution } & 1.3 & - & - & 376 & 545 & 2.56 \\
\hline & & & & 490 & 545 & 2.56 \\
\hline
\end{tabular}


phen are very efficient luminescent materials. Previously, ${ }^{8}$ we calculated the probability of the energy transfer, $P_{\mathrm{ET}}$, from the triplet states of phen to the rare earth ion with the exchange-interaction theory proposed by Dexter: for $\left[\mathrm{Eu}(\mathrm{ODA})(\text { phen }) \cdot 4 \mathrm{H}_{2} \mathrm{O}\right]^{+}, P_{E T}\left(\mathrm{~T} \rightarrow{ }^{5} \mathrm{D}_{2}\right) \cong 6 \times 10^{12} \mathrm{~s}^{-1}$ and $P_{E T}\left(\mathrm{~T} \rightarrow{ }^{5} \mathrm{D}_{1}\right) \cong 1.3 \times 10^{12} \mathrm{~s}^{-1}$, and for [Tb(ODA)(phen). $\left.4 \mathrm{H}_{2} \mathrm{O}\right]^{+}, P_{E T}\left(\mathrm{~T} \rightarrow{ }^{5} \mathrm{D}_{4}\right) \cong 3 \times 10^{13} \mathrm{~s}^{-1}$. The high quantumyield of the $\mathrm{Tb}(\mathrm{III})$ complex is due to the high energytransfer from phen.

For $\left[\mathrm{Eu}(\mathrm{ODA})_{3}\right]^{3-}$ and $\left[\mathrm{Tb}(\mathrm{ODA})_{3}\right]^{3-}$ complexes, the quantum yield of the solution state is almost the same as that of the crystalline state, while for $\left[\mathrm{Eu}(\mathrm{ODA})(\mathrm{phen}) \cdot 4 \mathrm{H}_{2} \mathrm{O}\right]^{+}$and $\left[\mathrm{Tb}(\mathrm{ODA})(\text { phen }) \cdot 4 \mathrm{H}_{2} \mathrm{O}\right]^{+}$complexes, the quantum yield decreases by more than 40 and $80 \%$, respectively, when the state changes from crystalline to solution. In the crystalline state, the fluorescence and phosphorescence of the phen moiety were not observed in the $\mathrm{Eu}(\mathrm{III})$ and $\mathrm{Tb}(\mathrm{III})$ complexes. It suggests that the energy transfer from the triplet states of phen to the lanthanide ion may predominate over any radiative and non-radiative processes occurring between the excited states and the ground state of the phen moiety. In solution state, however, the fluorescence and phosphorescence of the phen moiety were observed in the $\mathrm{Eu}(\mathrm{III})$ and $\mathrm{Tb}(\mathrm{III})$ complexes, as shown in Figure 6. It indicates that the energy transfer from phen to the lanthanide ion is reduced in aqueous state.

The luminescence decay times of the complexes in crystalline and solution states were also compared in Table 5. As listed in Table 5, the lifetimes of the mixed-ligand complexes are three times shorter than those of the homoleptic ones for both the $\mathrm{Eu}(\mathrm{III})$ and $\mathrm{Tb}(\mathrm{III})$ complexes in crystalline state. It could be due to that a deactivation channel may be present via the coordinated water molecules in the mixed-ligand complex. Previously, ${ }^{8}$ we estimated the rate constant, $k_{q}$, for the dynamic quenching responsible for the vibrational deactivation from the excited states of the lanthanide ion to water molecule: $k_{q}=2.7 \times 10^{3} \mathrm{~s}^{-1}$ for $\left[\mathrm{Eu}(\mathrm{ODA})(\mathrm{phen}) \cdot 4 \mathrm{H}_{2} \mathrm{O}\right]^{+}$and $k_{q}=8.1 \times 10^{2} \mathrm{~s}^{-1}$ for $\left[\mathrm{Tb}(\mathrm{ODA})(\text { phen }) \cdot 4 \mathrm{H}_{2} \mathrm{O}\right]^{+}$. As with the quantum yield, the

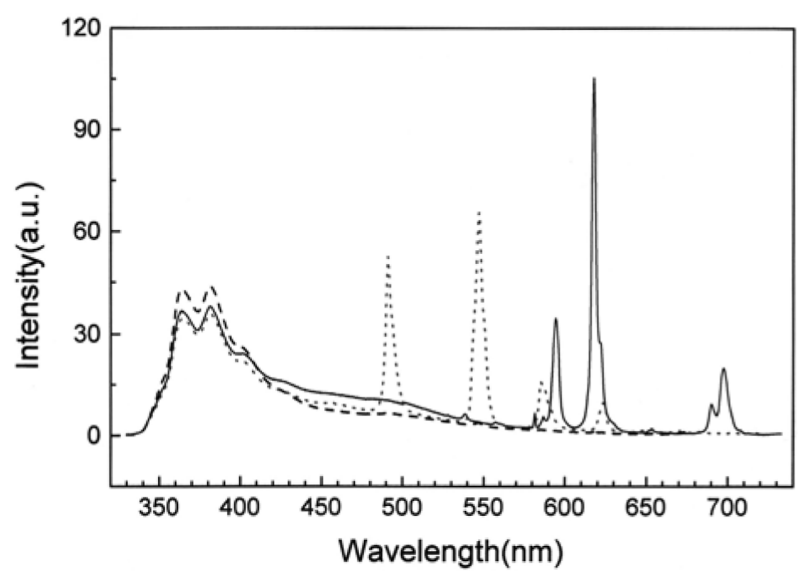

Figure 6. PL spectra of phen (dash line), $\left[\mathrm{Eu}(\mathrm{ODA})(\mathrm{Phen}) \cdot 4 \mathrm{H}_{2} \mathrm{O}\right]^{+}$ (solid line) and $\left[\mathrm{Tb}(\mathrm{ODA})(\mathrm{Phen}) \cdot 4 \mathrm{H}_{2} \mathrm{O}\right]^{+}$in aqueous state. solvation effect on the decay time can be found in [Eu(ODA) (phen) $\left.\cdot 4 \mathrm{H}_{2} \mathrm{O}\right]^{+}$and $\left[\mathrm{Tb}(\mathrm{ODA})(\text { phen }) \cdot 4 \mathrm{H}_{2} \mathrm{O}\right]^{+}$. For $[\mathrm{Eu}(\mathrm{ODA})$ (phen) $\left.\cdot 4 \mathrm{H}_{2} \mathrm{O}\right]^{+}$and $\left[\mathrm{Tb}(\mathrm{ODA})(\text { phen }) \cdot 4 \mathrm{H}_{2} \mathrm{O}\right]^{+}$, the decay of the crystalline complexes is slower than that of the solution state, while for $\left[\mathrm{Eu}(\mathrm{ODA})^{3}\right]^{3-}$ and $\left[\mathrm{Tb}(\mathrm{ODA})^{3}\right]^{3-}$, the decay time of the solution state is almost the same as that of the crystalline state. The bond between the rare earth ion and the divalent ODA anion is more rigid than that between the rare earth ion and the lone-pair electrons of $\mathrm{N}$ atoms of phen. Due to the rigid bonding, the solvation effects on the quantum yield and the decay rate are negligible in $\left[\mathrm{Eu}(\mathrm{ODA})_{3}\right]^{3-}$ and $\left[\mathrm{Tb}(\mathrm{ODA})_{3}\right]^{3-}$. In $\left[\mathrm{Eu}(\mathrm{ODA})(\mathrm{phen}) \cdot 4 \mathrm{H}_{2} \mathrm{O}\right]^{+}$and $[\mathrm{Tb}(\mathrm{ODA})$ (phen) $\left.\cdot 4 \mathrm{H}_{2} \mathrm{O}\right]^{+}$, however, the distance between phen and rare earth ion in the aqueous state is more relaxed than in the crystalline state. The relaxation may increase the distance between $\mathrm{Ln}(\mathrm{III})$, resulting in the reduction of the quantum yield and the deactivation involving water. The observed decay rate, $k_{o b s}$, from the emitting level of the complex in solution state is derived as

$$
k_{o b s}=\left(k_{r}+k_{n r}\right)+k_{d e}
$$

where $k_{r}$ and $k_{n r}$ are the radiative and the nonradiative rate constants, respectively, and $k_{d e}$ is the deactivation rate due to the solvent. Introducing the decay times, the Equation (5) can be further simplified as

$$
\frac{1}{\tau_{\text {obs }}}=\frac{1}{\tau_{\text {nsol }}}+\frac{1}{\tau_{\text {sol }}}
$$

where $\tau_{n s o l}$ is the decay time for the process in which the deactivation is not involved and $\tau_{\text {sol }}$ is for the case in which the deactivation is involved. For [ $\mathrm{Eu}(\mathrm{ODA})($ phen $\left.) \cdot 4 \mathrm{H}_{2} \mathrm{O}\right]^{+}$ and $\left[\mathrm{Tb}(\mathrm{ODA})(\mathrm{phen}) \cdot 4 \mathrm{H}_{2} \mathrm{O}\right]^{+}$, the difference between $k_{\text {obs }}$ of the crystalline state and solution states may equal the deactivation rate, $k_{d e}$. The average $k_{d e}$ values of [Eu(ODA) (phen) $\left.\cdot 4 \mathrm{H}_{2} \mathrm{O}\right]^{+}$and $\left[\mathrm{Tb}(\mathrm{ODA})(\text { phen }) \cdot 4 \mathrm{H}_{2} \mathrm{O}\right]^{+}$are 1.0 and 3.5 $\mathrm{ms}^{-1}$, respectively.

\section{Conclusion}

The single crystals of $\mathrm{Eu}(\mathrm{III})$ and $\mathrm{Tb}(\mathrm{III})$ complexes with mixed ODA and phen ligands and with homoleptic ODA produce well split luminescence lines. The energy-level splittings of the ${ }^{7} \mathrm{~F}_{\mathrm{J}}$ states of the $\mathrm{Eu}(\mathrm{III})$ and $\mathrm{Tb}$ (III) ions are satisfactorily simulated by the crystal-field Hamiltonian with the site symmetry determined from X-ray data. The crystalfield interaction of the mixed ODA and phen complex is weaker than that of the ODA complex. Due to the energy transfer from phen to the metal ion, however, the PL of the former is much more efficient than that of the later.

Acknowledgment. This work is funded by the Korean Science and Engineering Foundation (KOSEF R01-200100055).

\section{References}

1. Richardson, F. S. Chem. Rev. 1982, 82, 541. 
2. Bünzli, J.-C. G. Lanthanide Probes in Life, Chemical and Earth Sciences; Bünzli, J.-C. G.; Choppin, G. R., Eds.; Elsevier: Amsterdam, Oxford, New York, Tokyo, 1989; Chapter 7.

3. (a) McGehee, M. D.; Bergstedt, T. B.; Zhang, C.; Saab, A. P.; O’Regan, M. B.; Bazan, G. C.; Srdanov, V. I.; Heeger, A. J. Adv. Mater. 1999, 11, 1349. (b) de Sá, G. F.; Malta, O. L.; de Mello, Donegá, C.; Simas, A. M.; Longo, R. L.; Sata-Cruz, P. A.; da Silva, E. F. Jr. Coord. Chem. Rev. 2000, 196, 165. (c) Zheng, Y;; Fu, L.; Zhou, Y.; Yu, J.; Yu, Y.; Wang, S.; Zhang, H. J. Mater. Chem. 2002, 12, 919 .

4. (a) Fronczek, F. R.; Banerjee, A. K.; Watkins, S. F.; Schwartz, R. W. Inorg. Chem. 1981, 20, 2745. (b) Albin, M.; Whittle, R. R.; De, W.; Horrocks, W. Jr., Inorg. Chem. 1985, 24, 4591. (c) Schoene, K. A.; Quagliano, J. R.; Richardson, F. S. Inorg. Chem. 1991, 30, 3803. (d) Metcalf, D. H.; Hopkins, T. A.; Richardson, F. S. Inorg. Chem. 1995, 34, 4868.

5. Kang, J.-G.; Kim, T.-J.; Park K. S.; Kang, S. K. Bull. Korean
Chem. Soc. 2004, 25, 337.

6. Kim, K.-B.; Kim, Y.-I.; Chun, H.-G.; Cho, T.-Y.; Jung, J.-S.; Kang, J.-G. Chem. Mater. 2002, 14, 5045.

7. de Mello, J. C.; Wittmann, H. F.; Friend, R. H. Adv. Mater. 1997, 9, 230.

8. Kang, J.-G.; Kim, T.-J.; Kang, H.-J.; Kang, S. K. J. Photochem. Photobio. A 2005 (in press).

9. (a) Handbook of the Physics and Chemistry of Rare Earths; Thompson, L. C., Eds.; North-Holland: Amsterdam and New York, 1979; V. 3, Chapter 25. (b) Mirochnik, A. G.; Bukvetskii, B. V.; Zhikhareva, P. A.; Karasev, V. E. Russ. J. Coord. Chem. 2001, $27,443$.

10. Wybourne, B. G. Spectroscopic Properties of Rare Earths; Interscience Pub.: New York, London, Sydney, 1965; Chapter 6.

11. (a) Chang, N. C.; Gruber, J. B.; Leavitt, R. P.; Morrison, C. A. J. Chem. Phys. 1982, 76, 3877. (b) Leavitt, R. P. J. Chem. Phys. 1982, 77, 1661. 